\title{
DIFUSÃO DE TECNOLOGIA DE ENSILAGEM ATRAVÉS DA CONFECÇÃO DE CARTILHA DIDÁTICA
}

\author{
Luis Moreira de Araujo Junior ${ }^{1}$; Dayanne Lustosa Mororó ${ }^{\text {; }}$ Alzira Gabriela da Silva Pause ${ }^{2}$; \\ Rosana Quaresma Maneschy ${ }^{3}$ \\ ${ }^{1}$ Discente do curso de Agronomia, Faculdade de Ciências Agrárias de Marabá (FCAM), Universidade Federal do Pará \\ (UFPA), Bolsista PIBEX, luisjrmoreira@hotmail.com, ayanne_mba@hotmail.com \\ ${ }^{2}$ Zootecnista, D. Sc., FCAM, UFPA, alziragabi@ufpa.br \\ ${ }^{3}$ Engenheira Agrônoma, D. Sc., FCAM, UFPA, romaneschy@ufpa.br
}

\begin{abstract}
RESUMO: Em um processo de difusão de tecnologia, para que uma cartilha seja adequadamente compreendida pelo leitor, é necessário que os elementos abordados tenham correspondências à realidade do público alvo. Com o propósito de fixar a tecnologia de ensilagem aos agricultores familiares do projeto de assentamento (P. A.) Belo Horizonte, São Domingos do Araguaia - PA objetivou-se elaborar uma cartilha didática adaptada a realidade local da comunidade. A difusão da tecnologia de ensilagem teve início em janeiro de 2009. Neste ano foram realizadas palestras, reuniões e implantação de módulos demonstrativos de banco forrageiro de milheto (Pennisetum glaucum (L.) R. Brown) para a ensilagem. Para complementar o processo de difusão dessa tecnologia, em 2010 foi elaborada uma cartilha com o intuito de fixar os conhecimentos técnicos adquiridos no ano anterior. Na elaboração da cartilha foi levado em consideração à experiência vivida no P. A. durante a implantação dos módulos demonstrativos de banco forrageiro de milheto destinado a ensilagem. Os assuntos abordados foram referentes ao conceito de silagem e ensilagem, e como determinar a sua produção. Na impressão da cartilha foi utilizado papel reciclado por ser um material ecologicamente correto. A confecção da cartilha ocorreu de forma didática, uma vez que foi utilizado um texto com linguagem acessível ao entendimento dos agricultores. A cartilha foi ilustradas com figuras para a representação visual de cada etapa da ensilagem, a fim de facilitar o processo de fixação do conhecimento técnico referente à aplicação da tecnologia.
\end{abstract}

PALAVRAS-CHAVE: Agricultura familiar, ensilagem, fixação de conhecimento, Penisetum glaucum.

\section{DIFUSIÓN DE TECNOLOGÍA MEDIANTE DE ENSILAJE ENSILAJE A TRAVÉS DA CONFECCIÓN DE CARTILLA DIDÁCTICA}

RESUMEN: En un proceso de difusión de la tecnología, de modo que una cartilla sea bien entendida por el lector, es necesario que los temas se coincide con la realidad del público. Con el objetivo de establecer la tecnología de ensilado a los agricultores familiares del proyecto de asentamiento (P. A.), Belo Horizonte I, São Domingos do Araguaia - PA, se objetivó elaborar una cartilla didáctica adaptada a realidad de la comunidad local. La difusión de la tecnología de ensilado se inició en enero de 2009. Este año se llevaron a cabo conferencias, reuniones y la implementación de módulos de estados de cuenta bancarios de forraje de Pennisetum glaucum (L.) R. Brown para ensilaje. Para complementar el proceso de difusión de esta tecnología en 2010 un folleto ha sido preparado con el fin de fijar los conocimientos técnicos adquiridos en años anteriores. En la preparación del folleto se tuvo en cuenta la experiencia en el P. A. durante la implementación de módulos de banco de forraje de P. glaucum destinado para ensilaje. Los temas tratados fueron relacionados con el concepto de ensilaje y forraje, y de cómo determinar su producción. En la impresión del folleto se utilizó papel reciclado por ser un material ecológico. La preparación del 
folleto ocurrió de manera didáctica, utilizando un texto con lenguaje accesible a comprensión de los agricultores. La cartilla fue ilustrada con cifras para la representación visual de cada etapa del ensilaje, con el fin de facilitar el proceso de fijación de los conocimientos técnicos relacionados con la aplicación de la tecnología.

PALABRAS-CLAVE: Agricultura familiar, ensilaje, fijación de los conocimientos, Penisetum glaucum.

\section{INTRODUÇÃO}

O termo assentamento que surgiu pela primeira vez no contexto da reforma agrária venezuelana em 1960 foi posteriormente difundido em vários países. Ele se refere a unidades de produção agrícolas resultantes do processo de reforma agrária, em que se constituiu no lugar de vida e trabalho das famílias beneficiadas, com a finalidade de proporcionar à justa distribuição da terra, com o seu uso destinado ao bem estar social (VEIGA, 1984).

A produção de leite transformou-se em uma importante atividade econômica no Sudeste do Pará, uma vez que se constituiu no segmento comercial mais expressivo para a agricultura familiar (ALVES, et al., 2006). Porém, a disponibilidade de forrageira para a alimentação do rebanho, em especial a bovina leiteira, é alterada em função da sazonalidade, em que se tem bastante forragem de boa qualidade no período chuvoso do ano e escassez da mesma no período seco. A ensilagem, que consiste na tecnologia de produção de volumoso conservado via fermentação (silagem), apresenta-se como uma alternativa viável para garantir uma alimentação de melhor qualidade nos períodos críticos no ano, por permitir o armazenamento do excesso de forragem produzida durante o momento de seu maior crescimento (NOVAES et al., 2004).

No processo de difusão de tecnologias, o uso de cartilhas é considerado uma técnica pedagógica relevante, uma vez que o agricultor poderá recorrer a este material sempre que for necessário durante a aplicação do conhecimento difundido. Entretanto, para que a cartilha seja adequadamente compreendida pelo leitor é necessário que os elementos abordados tenham correspondências à realidade do público alvo (BACELAR et al., 2009). Com o propósito de fixar a tecnologia de ensilagem aos agricultores familiares do projeto de assentamento (P. A.) Belo Horizonte, São Domingos do Araguaia - PA objetivou-se via condução deste trabalho, elaborar uma cartilha didática adaptada a realidade local da comunidade.

\section{MATERIAL E MÉTODOS}

A tecnologia de ensilagem foi proposta pelo Projeto de Extensão: "Introdução de 
bancos forrageiros de alta qualidade e da prática de confecção de silagem com gramíneas e leguminosas no Assentamento Belo Horizonte, São Domingos do Araguaia, Pará", que está no seu segundo ano de atuação, vinculado a Pró-Reitoria de Extensão (PROEX) da Universidade Federal do Pará. O P. A. Belo Horizonte está situado no km 30 da BR-153, no município de São Domingos do Araguaia, pontuado geograficamente pelas coordenadas $5^{\circ} 47^{\prime} 15,4^{\prime \prime} \mathrm{S}$ e $48^{\circ} 39^{\prime} 26,9^{\prime \prime} \mathrm{W}$.

$\mathrm{Na}$ difusão da tecnologia de ensilagem, durante o primeiro ano de atuação do projeto, foram primeiramente desenvolvidas atividades de testes em meio real em parcerias com agricultores do P. A., conforme a metodologia descrita por Chia et al. (2006) em que também foi utilizada a metodologia da pesquisa-ação com abordagem participativa (FRAPPAT et al., 2005). Essa ação-teste foi escolhida por sete famílias de agricultores. Considera-se como ação-teste quando guiado por um facilitador os agricultores realizam um pequeno ensaio teste em parcelas pequenas, as quais podem ter diferentes tratamentos (CIAT, 1993). Em janeiro de 2009 foram promovidas palestras, com assuntos relativos à ensilagem e reunião para a escolha da gramínea como banco forrageiro para a confecção de silagem.

Os pesquisadores membros do projeto sugeriram as seguintes gramíneas: o milheto (Pennisetum glaucum (L.) R. Brown) e o sorgo
(Sorghum bicolor L. Moench), como banco forrageiro para a confecção de silagem. Os agricultores escolheram o milheto e indicaram as duas famílias para a implantação de um módulo demonstrativo em cada estabelecimento.

O plantio foi realizado no mês de março de 2009, em linhas (de $20 \mathrm{~m}$ de comprimento) espaçadas de 0,40 m entre linhas, em uma área total de $400 \mathrm{~m}^{2}$. Foram consideradas bordaduras: as linhas externas e $0,50 \mathrm{~m}$ nas extremidades, resultante na área útil de cada módulo. A profundidade utilizada foi de 0,20 $\mathrm{m}$ com uma taxa de semeadura de 20 sementes puras viáveis (SPV) por metro linear.

No período de 85 dias após a germinação, as plantas da área útil de cada módulo foram cortadas manualmente, a uma altura de dez centímetros da superfície do solo, quando os grãos apresentavam-se no estádio farináceo. O estádio de maturação dos grãos foi avaliado na parte mediana da panícula. O material colhido foi picado em partículas de 1,0 e 2,0 cm, com um desintegrador estacionário de propriedade de um agricultor vizinho do P. A. Após homogeneização do material picado, este foi transportado para o local de armazenamento, onde foi acondicionado em um silo de superfície, moldado por um tambor de 200 litros, compactado e vedado com uma lona de 150 mícron. 
No segundo ano de atuação do projeto, com o intuito de fixar os conhecimentos técnicos referentes à tecnologia de ensilagem, foi elaborada uma cartilha com texto de fácil entendimento e figuras baseadas em imagens de agricultores em efetuação das etapas da produção de silagem.

\section{RESULTADOS E DISCUSSÃO}

O levantamento de dados para a confecção desta cartilha ocorreu através do trabalho coletivo entre pesquisadores $\mathrm{e}$ agricultores do P. A Belo Horizonte. E para a sua elaboração foi levado em consideração à experiência vivida no P. A. durante a implantação dos módulos demonstrativos de milheto forrageiro para a ensilagem, uma vez que, esta experiência tende a facilitar a compreensão dos processos de produção de silagem descritos na literatura (FREIRE, 1983).

De acordo com Bacelar et al. (2009), uma cartilha deve ser de preferência, um projeto coletivo, por meio de uma construção dialógica, resultado do trabalho em equipe multidisciplinar. Isto porque a articulação de saberes é fundamental na geração de um produto holístico ao passo que se concebido de forma disciplinar, teria uma visão fragmentada. Contudo, para que seja bem- sucedido o uso de uma cartilha, é preciso que seja focada numa realidade específica, neste caso a do P. A. Belo Horizonte.

A cartilha foi elaborada com a utilização de uma linguagem verbal acessível à compreensão dos agricultores, em que foi utilizado um vocabulário presente no seu diaa-dia, entretanto, com caráter técnico. Cada linguagem, tanto em termos de seu léxico como de sua estrutura, representa uma maneira singular de perceber a realidade.

Segundo Freire (1983) a adaptação da linguagem, em um processo de difusão de tecnologia é importante para que haja uma comunicação entre o autor e o leitor. A comunicação por sua vez, envolve basicamente três ações: codificação, transmissão e decodificação de uma mensagem.

A aprendizagem só ocorre quando esta mensagem é devidamente recepcionada e incorporada pelo indivíduo. Por isso deve-se buscar uma maneira adequada de codificação e transmissão da mensagem. Portanto, o texto presente nas cartilhas deve: ser sucinto; possuir linguagem simples e ser adequado ao nível técnico dos leitores. Neste sentido, o texto da cartilha foi estruturado conforme mostra o fluxograma dos assuntos abordados na cartilha (Figura 1). 


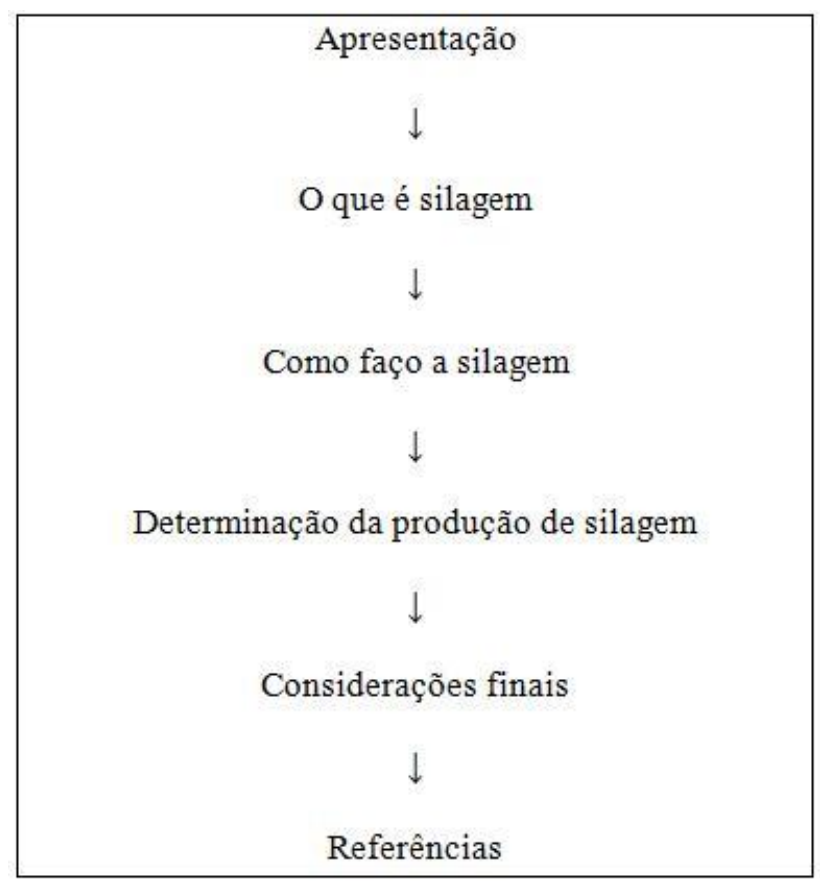

Figura 1. Fluxograma dos assuntos abordados na cartilha.

As etapas da ensilagem do milheto, que consistem em corte, transporte, trituração, compactação e vedação do material picado, foram ilustradas através de figuras desenhadas manualmente. Ilustrações são imagens ou desenho que acompanham texto de publicação. O seu uso é útil devido às seguintes razões: reproduz, em muitos aspectos a realidade; facilita a percepção de detalhes; reduz ou amplia o tamanho real dos objetos representados; torna próximos fatos e lugares distantes no espaço e no tempo e; permite a visualização imediata de processos muito lentos ou rápidos (BACELAR et al., 2009). Apesar da linguagem simples utilizada na cartilha, o emprego da ilustração foi importante para auxiliar os agricultores na fixação de como proceder em cada etapa da ensilagem. De acordo com Costa et al. (2007), à medida que se visualizam os eventos, a compreensão se torna menos abstrata e mais rápida.

$\mathrm{Na}$ impressão da cartilha foi utilizado papel reciclado por ser um material ecologicamente correto. A produção de papel reciclado apresenta várias vantagens, dentre elas destacam-se as seguintes: redução dos custos das matérias-primas e economia de recursos naturais, como a madeira, uma vez que uma tonelada de aparas pode substituir de 2 a $4 \mathrm{~m}^{3}$ de madeira, conforme o tipo de papel a ser fabricado, o que se traduz em uma nova vida útil para de 15 a 30 árvores (FERRAZ, 2009). 


\section{CONCLUSÕES}

A elaboração da cartilha ocorreu de forma didática, uma vez que foi utilizado um texto com linguagem acessível ao entendimento dos agricultores e figuras ilustradas manualmente para a representação visual de cada etapa da ensilagem, a fim de facilitar o processo de fixação do conhecimento técnico referente à aplicação da tecnologia. A distribuição da cartilha será realizada no final do ano de 2010, quando será realizada a restituição dos dados.

\section{REFERÊNCIAS}

ALVES, L. N.; RODRIGUES, M. da S.; SCHERER, R. dos S. O arranjo produtivo do leite do Sudeste do Pará. Marabá: UFPA/LASAT/CNPq. 2006. 40 p.

BACELAR, B. M. F.; PINHEIRO, T. S. M.; LEAL, M. F.; PAZ, Y. M.; LIMA, A. S. T.; ALBUQUERQUE, C. G.; CORRÊA, M. M.; CORDEIRO, I.; SILVA, V. L.; EL-DEIR, S. Metodologia para elaboração de cartilhas em projeto de Educação Ambiental em micro e pequenas Empresas. In: IX JORNADA DE ENSINO, PESQUISA E EXTENSÃO. Anais. Recife, 2009. (CD-ROM).

CHIA E., DUGUÉ P., SAKHO-JIMBIRA S. Les exploitations agricoles familiales sontelles des institutions? In Agricultures, Montpellier, v. 15, n. 6, 2006, 498-505 p.

CIAT. Centro Internacional de Agricultura Tropical. Cartillas para CIAL (Comités de Investigación Agrícola Local :O ensayo. Cali: CIAT/IPRA, 1993. 43 p.

COSTA, E. C.; CARVALHO, H. M. B.; HAHN, T. T.; COSTA, J. C.; SOUTO, L. V.; GRESSLER, C. C.; OLIVEIRA, M. A. C.; COELHO, G.; TROJAHN, L.; BOLZAN, P.
O.; PONTES, G.; BOTELHO, M. Z.; RIBEIRO, D.; MORAIS, C. M. B.; GRACIOLI, M. S. A. Elaboração e promoção de uma cartilha informativa interdisciplinar para pacientes em terapia de câncer e seu familiares. In: XII CONGRESSO BRASILEIRO DE FÍSICA MÉDICA. Anais. Foz do Iguaçu, 2007. (CD-ROM).

FERRAZ, J. M. G. O papel nosso de cada dia. Jaguariúna: Embrapa Meio Ambiente, 2009. 5 p. Disponível em: < http://www.embrapa.gov.br/imprensa/artigos/ 2009/O\%20papel\%20nosso\%20de\%20cada\% 20dia_JoseMaria.pdf >. Acesso em: $08 \mathrm{de}$ outubro de 2010.

FRAPPAT B., DOCKES A.C., SOUQUET C., LACOUR C. Les attentes et besoins des éleveurs de bovins en matière de conseil. Actes des Rencontres recherches Ruminants. Paris, 2005, 5 p.

FREIRE, PAULO. Extensão ou comunicação?. 7 ed. Rio de Janeiro: Paz e Terra, $1983.93 \mathrm{p}$.

NOVAES, L. P.; LOPES, F. C. F.; CARNEIRO, J. C. Silagens: oportunidades e pontos críticos. Juiz de Fora: Embrapa Gado de Leite, 2004. 10 p. (Comunicado Técnico, 43).

VEIGA, J. E. O que é reforma agrária. São Paulo: Abril Cultural Brasiliense, 1984. 87 p.

\section{AGRADECIMENTOS}

O presente trabalho foi realizado com o apoio da Pró-Reitoria de Extensão - PROEX da Universidade Federal do Pará - UFPA. 